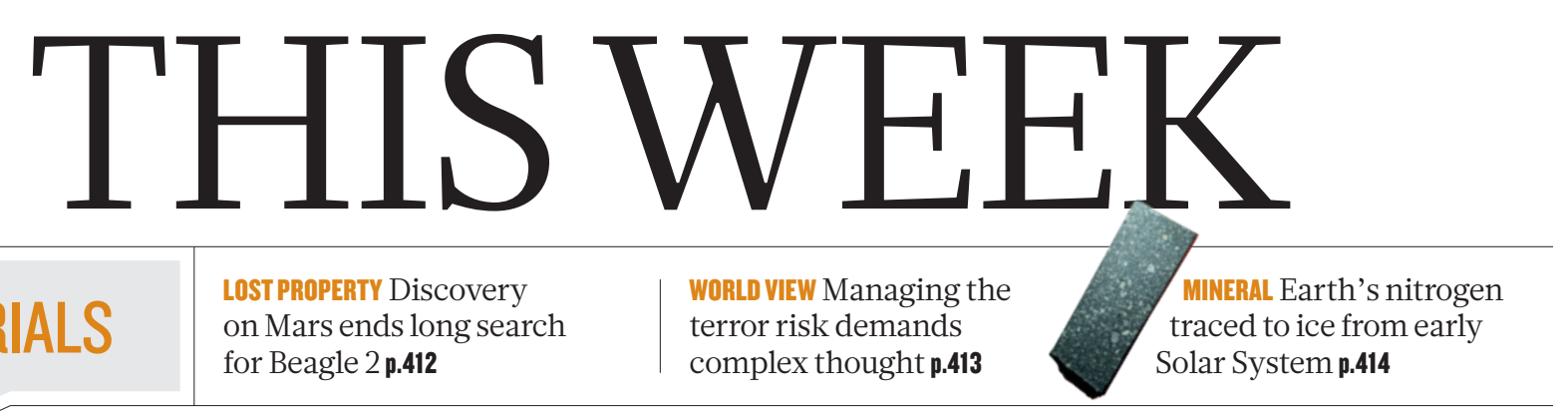

EDITORIALS for Beagle 2 p.412 terror risk demands complex thought $\mathbf{p . 4 1 3}$

\title{
Kept on a leash
}

\section{A vital dependence of genetically modified organisms on an artificial nutrient could be a means of preventing their escape into the environment.}

$\mathrm{O}$ f all the concerns and complaints about the use of genetically modified organisms (GMOs), one of the most legitimate has always been the threat of pollution. Life will, after all, find a way. And genetically altered life is no different. From super-weeds made resistant to herbicides, to contamination of food with genetically modified ingredients, it has proved difficult to keep the technology fully contained.

The risks posed by the unintended spread of GMOs are uncertain, but they are infinitely lower than the nightmare scenarios painted by opponents. Yet in many respects that is beside the point. As this journal has pointed out before, public opinion matters here, whether or not scientists think that the basis for that opinion is misguided. Researchers who would create and release GMOs have a duty - ethical and often statutory or regulatory - to minimize the collateral impact on those who do not share their enthusiasm for the technology. Most, of course, already take that responsibility seriously. But many of the promised benefits of genetic modification, from the development of new fuels and medicines to more-durable crops, demand broad deployment outside the laboratory. And outside the laboratory, things can and do go wrong.

If genetic modification cannot be kept in its box, then can it be kept on a leash? Two papers published this week on Nature's website offer hope that it can be. In principle, the techniques described in the papers could defuse the major concerns about GMO pollution. But, depending on how the science is applied, they could exaggerate some of the separate worries about the social and economic impact that continue to dog the commercial application of genetic modification, in Europe in particular.

The new approach gives GMOs an Achilles heel. The researchers who have produced the organism have built in vital dependency on an artificial nutrient. If the nutrient is withdrawn, or the organism spreads to where it is no longer available, then the organism cannot survive. Pull too tightly on the leash and it turns into a noose.

The research marks an elegant step forward for the growing field of synthetic biology. In the first paper, Farren Isaacs and his colleagues at Yale University in New Haven, Connecticut, describe how they have produced various GMOs whose growth is restricted by the expression of multiple essential genes that depend on synthetic amino acids (A. J. Rovner et al. Nature http://dx.doi.org/10.1038/ nature14095; 2015). In the second, separate study, George Church at Harvard Medical School in Boston, Massachusetts, and his colleagues redesigned essential enzymes in a GMO to make it metabolically dependent on synthetic amino acids (D. J. Mandell et al. Nature http://dx.doi.org/10.1038/nature14121; 2015). The modifications are made throughout the genome to make it harder for the altered sequences to be ejected.

More details of the science are included in a News story on page 423. In both cases, the organisms cannot use alternative nutrients as a supplement when the synthetic amino acids are unavailable, and they seem to be resistant to mutations that improve their survival in the wild, thanks to the multiple sites of genetic modification. In theory, these features make the control of GMOs more effective than with current techniques. The research in both papers is with bacteria, but there seems no reason why the techniques they describe could not be used to engineer more-complex, multicellular organisms - including
"It is important not to gloss over concerns, however irrational they may seem to some."

$$
\text { crops - in the same way. }
$$

So what is the downside? Much of the controversy over genetic modification relates to early, clumsy, attempts by big business to commercialize crops, and to gain control over where, when and how they were grown to maximize profit. A crop that needs constant nourishment with a bespoke foodstuff - unavailable elsewhere and with manufacture protected under probable patents - could be presented as a way of tying vulnerable farmers still closer to largely unloved seed companies.

It is early days, but is it too early to consider such a scenario? Yes and no. As the researchers correctly point out, the technology could most immediately be useful for containing GMOs used in research and industrial systems - microbes typically - to make high-value pharmaceuticals, for example. But applications in crops are some way off.

Still, perceptions matter, and it is important not to gloss over concerns, however irrational they may seem to some. Last week, the European Union agreed on compromise legislation that might settle more than a decade of disagreement and allow research and development on GMOs to proceed (see Nature 516,$143 ; 2014$ ). The new research can address an old fear - contamination - that contributed to the controversy. But it is prudent to consider other anxieties that might sprout in its place.

\section{Down to earth}

\section{A concerted focus on soils will benefit society in untold ways and should be embraced.}

$\mathrm{T}$ The year 2015 carries many titles. For physics fans, it is the International Year of Light, marking 100 years since Albert Einstein developed his general theory of relativity. For development experts, it is the International Year of Evaluation, a time to promote evidence-based policy-making.

But 2015 also bears earthier significance. The Food and Agriculture Organization of the United Nations (FAO) has decreed 
it the International Year of Soils. Britain's leading Earth-sciences organization, the Geological Society in London, has also proclaimed it the Year of Mud. Just add rain. And, as visitors to Nature's national and spiritual home can very often attest, what is soil to the world is mud in Britain.

Wet or dry, such dirty pursuits offer an important opportunity to highlight an oft-forgotten corner of the research world. Mud and soil science underlie many of the questions facing our planet, from how to feed billions of people to how to keep them safe from floods, fires and other natural disasters. Nature has long argued that researchers must be on the front lines of turning soil discoveries into practical advances. In 2012, one of our journalists travelled to Malawi to analyse the best ways to enrich African soil (see Nature 483, 525-527; 2012). Last week, we assessed the often-overhyped promise of biochar, burnt agricultural material meant to improve the performance of soils that it is mixed into (see Nature 517, 258-260; 2015).

The goal of the Year of Soils is to make others aware as well, and it offers a chance to marshal research initiatives to answer some of the most pressing questions. For instance, the FAO is focusing on updating and revising soil maps around the globe. 'Legacy' maps from Afghanistan to Zimbabwe have been scanned and made available online, providing key historical data for understanding how land use has changed over time. Looking ahead, an international consortium is working on producing a digital global soil map, georeferenced down to 100 metres.

Figuring out which soils lie where is just the first step; after that comes saving the best of what is left. The FAO estimates that an area of soil the size of Costa Rica is lost every year to factors such as erosion, compaction and salinization. One-third of the world's soils have already been degraded, often in the countries that can least afford to lose that resource. When soil becomes sicker, so too do the people who rely on it. Contamination soars and crop yields and human health decline.

Somehow, researchers must also figure out a way for farmers to feed ever-increasing populations on ever-shrinking amounts of arable land. The solutions must take cost into account, because what works in the lab will not work in the field if the soil-treatment or conservation approach is too expensive for the people who need it most.

Against such enormous societal problems, the Geological Society's decision to focus on mud might at first elicit a snigger: mud is a problem to face with wellies, not with a global research agenda. But take

"When soil becomes sicker, so too do the people who rely on it."

\section{vertebrate evolution. Without small creatures} drowning in and being encased by mud, we would have a much harder time unravelling the relationship between organisms past and present.

Then there is the economic importance of mud-based rocks. Petroleum engineers have been exploring shale as a future source of both oil and natural gas. Although controversy rages about how much shale gas might ultimately be available (see Nature 516, 28-30; 2014), extraction rates have soared in the United States, driven by big reserves such as the Marcellus Shale underlying much of Pennsylvania and neighbouring states. In March, industry and academic experts will gather in London to assess the numbers behind a possible ramp-up in shale-resource production in the United Kingdom.

Finally, consider how soil and mud combine to underpin many of the globe's natural disasters. Assessing flood risk requires knowing what soils are where, and how likely they are to turn to mud in times of heavy downpours.

Now is the time to drill down hard on the big questions for soil science. Not all annual focuses are as relevant for society: 2016 has already been designated the International Year of Camelids.

\section{Lost and found}

\section{The discovery of Beagle 2 on Mars should spur the search for other items lost to science.}

$\mathrm{A}$ $n$ odd idiom in the English language points out that when an object is mislaid, it will turn up "always in the last place you look for it". Space scientists never stopped looking for Beagle 2, the probe that vanished when British researchers tried to land it on Mars in 2003, and last week their persistence paid off. A tiny, shiny smudge in a high-resolution image of the red planet, taken by NASA's Mars Reconnaissance Orbiter (MRO), is very probably the missing spacecraft, the researchers told a press conference in London.

The blurry pictures suggest that the shoestring mission, costing some $£ 50$ million (US\$76 million), did better than many have suggested. It is impossible to be sure, but the craft's complicated entry, descent and landing sequence - which involved a parachuted descent followed by a series of bounces cushioned by airbags - seems to have worked as planned. Landing intact on the planet's surface, the probe then probably failed to open all of its solar panels properly, leaving it unable to call home. The exact reason for this will probably remain a mystery. Perhaps the lander hit a rock, or arrived at a faster pace than it should have (data suggest the planet's atmosphere was thinner than expected), or maybe one of the airbags failed to detach and got in the way.

If the British team was unlucky then, it is fortunate now. When the press conference was announced - but not the reason for it - some commentators scoffed at the suggestion that the spacecraft had been found. Measuring just 2 metres across, Beagle 2 was found stranded in a landing zone some 60 kilometres long and 10 kilometres wide. Although the scientists have examined photos of the Martian surface for years, the find only became a realistic possibility with the 2006 arrival in orbit of the MRO's HiRISE camera, which has a pixel resolution of about 25 centimetres.

The discovery, and the signs that the probe fell only at the final hurdle, marks a victory of sorts for the mission, which was launched by a group of British universities and headed by the media-savvy researcher Colin Pillinger, who died last year. Some space scientists who were critical of the low-budget mission unfairly confused the team's enthusiasm and determination for amateurism - including the European Space Agency, which published a scathing report on the lander's loss in 2004. Bad luck can skewer even the most costly space missions.

At the very least, the happy ending to the decade-long search should encourage others to keep looking for their own missing equipment, artefacts and specimens. For a precise pursuit, science can be surprisingly sloppy. It is easy, one can concede, to get lost in space, but we should be more careful on Earth. NASA, for example, complained in 2012 that dozens of pieces of its Moon rock, brought back by Apollo astronauts and distributed along with other space samples as tokens of goodwill to US states and foreign nations, have been mislaid. Fragments of meteorites have been lost in the post, and a valuable chunk of Moon collected by the Apollo 11 mission is believed to have been discarded on a rubbish tip in Ireland.

Last month, the University of Texas at Austin said that it was search-
D NATURE.COM To comment online, click on Editorials at: go.nature.com/xhunqv ing for 100 human brains that had been lent to its psychology department by a local hospital in the 1980s, but were now unaccounted for. One thing is certain: they will be in the last place the university thinks to look. 